Niklas Franzen

\title{
"Jupiter and Beyond the Infinite" as Social Reflection? The Success of the Sequence Among Young Adults of the Counterculture
}

\section{Introduction}

Stanley Kubrick's motion picture 2001: A Space Odyssey is one of the most successful and legendary films in cinematic history. Its release in 1968 earned the thirdbest box office gross and a total of $\$ 138$ with its initial and subsequent releases. It has been acknowledged as one of the greatest movies ever made, and in 2002 the British film magazine Sight \& Sound ranked it among the top ten films of all times.

2001 has marked "a turning point in the science fiction film genre" (Cornea 87) and by Hollywood standards it certainly was a radical innovation. The film attracted a remarkable amount of critical attention, "but critical opinion was markedly divided when it was first shown in America" (83). The controversy about the film becomes especially apparent in the final sequence, "Jupiter and Beyond the Infinite." Therefore I will narrow down my analysis to this particular sequence.

"Jupiter and Beyond the Infinite," also known as the Stargate sequence, begins with impressive shots of a black monolith in orbit around Jupiter. When astronaut Dave Bowman leaves the spacecraft in a pod to approach the monolith, he finds 
himself suddenly racing through a tunnel of colorful light sequences. During the journey, strange astronomical entities are shown and the voyage concludes with views on the surface of an oddly colored planet. Eventually Bowman is shown in a room decorated in old Renaissance style, where he discovers older versions of himself, with the visual angle each time switching to the older Bowman. Ultimately an ancient and deceasing Bowman is shown lying in a canopy bed, with a black monolith on its foot, and the old Bowman is transformed into a fetus-like creature, the Star Child. The last scene shows the Star Child floating in space, looking down on earth.

According to Christine Cornea, the release of 2001 in 1968 "responded to the zeitgeist of the era and assured its eventual success at the box office" (83). Barton R. Palmer has pointed out that especially young people flocked the country's theaters, "turning the film's exhibition into one of the signal cultural events of the decade" (13).

In this paper, I will pursue the questions of why "Jupiter and Beyond the Infinite" in particular has been so popular among young viewers and of how the sequence became a means of opposition and subversion of the 1960s counterculture. I will therefore begin my analysis with an account of the historical background of the 1960s. After that, I will closely examine the sequence, considering psychedelic, drug-related interpretations and the use of subversive cinematic devices. By discussing the social perception of the film, I will then seek to answer my initial question and conclude my paper with a summary of my findings.

\section{From Frustration to Counterculture: The USA in the 1960s}

The decade began with optimism carried over from the economic boom of the 1950s, and was enhanced by newly elected President John F. Kennedy. Events like the Cuban missile crisis, which brought the world to the edge of nuclear annihilation, the assassinations of major figureheads (John F. Kennedy, 1963; Malcolm X, 1965) and America's entering the Vietnam War however shattered much of this optimism in the mid 1960s.

The attempt to demonstrate unity in the space race against the Soviet Union and in the intensifying Cold War failed, and a variety of protest movements swept American society, challenging government policies and middle-class values and lifestyles. Bruce J. Schulman claims that " $[\mathrm{f}]$ rustration and alienation pushed Americans toward the counter-culture, but also exerted a strong pull of its own: the conviction that it was possible to drop out of the polluted, corrupt mainstream and live according to one's values" (qtd. in Cornea 89-90).

The year 1968 is often considered as the peak of social and political unrest and to this day serves as symbol for revolt and for the conflict between what was regarded as counterculture and establishment. Stanley Kubrick's controversial film 2001: A Space Odyssey was also released in this tumultuous year. I will therefore 
focus my examination of the historical background particularly on the year 1968 . My argumentation will be based on the analysis of three major events that heavily affected the American social development and turned 1968 to the year that changed history.

\section{Vietnam: Between Trauma and Protest}

On the 30th of January 1968 the North Vietnamese troops launched a major military offensive against South Vietnam and their American allies, what later came to be known as the 'Tet Offensive.' The offensive ended with nearly 4000 U.S. troops dead and with the irrevocable conviction that this war was not going to be won. The military intervention of the USA in Vietnam began in 1965 following a war fought between South Vietnam and communist North Vietnam (the Democratic Republic of Vietnam) that sought to overthrow the Southern Vietnamese government and unify the country under rule of Ho Chi Mihn. The United States supported Southern Vietnamese premier Ngo Dihn Diem because of their Cold War policy of containment of the spread of communism. The belief of a great number of Americans was that "if South Vietnam fell to communism, it would then spread to neighbouring countries, which would fall like a row of dominoes" (Trevino 122). By the end of 1968 more than half a million American soldiers were in action.

The public opposition to the war in Vietnam began in 1964 on college campuses across the country and increased in size and intensity as the Vietnam conflict continued and American soldiers were shipped out and died. The most visible representatives of the antiwar movement were the hippies. With their recognizable appearance and rejection of mainstream behavior and culture, the so-called flower people rebelled peacefully against the conservative foundations of U.S. society with a mix of rock music, drug use and frequent sexual activities.

But not only had the hippies taken to the streets at that time to protest U.S. involvement in the conflict and the war-mongering political culture. Members of the New Left, black civil rights activist and even soldiers and veterans also expressed their fierce opposition to the U.S. American military policy. When in March 1968 an American Army Division massacred hundreds of civilians in the village of My Lai, the American public was outraged and the peace movement reached its peak of strength. As Chino Fernandez puts it: "At the same time the Vietnam War was raging, the seeds of change were being sown in homeland United States" (112). 


\section{Civil Rights Movement: Hope and Setback}

On the evening of April 4th 1968 Dr. Martin Luther King was murdered by James Earl Ray on the balcony of Lorraine Hotel in Memphis. In response, violence broke out in many American cities and over forty people were killed. A nation was stunned and the Civil Rights Movement had to mourn the loss of one of its symbolic figures.

The Civil Rights Movement grew out of the struggle of black Americans to obtain long denied constitutional rights and to end racial segregation in American society. In the early 1960s, the movement could produce considerable successes like the March on Washington, where Baptist priest and civil rights leader Martin Luther King gave his famous speech "I have a dream", which was followed by the signing of the Civil Rights Act in 1964 that prohibited a greater part of discrimination based on race, color and religion. Yet, endeavors to end discrimination in the United States were continuously overshadowed by terror and persecution against African Americans and civil rights activists, and by the still visceral racism in the USA, especially in the South. Organisations like the National Association for the Advancement of Colored People (NAACP) and King's Southern Christian Leadership Conference (SCLC) tried to overcome racism and discrimination in a nonviolent way and propagated civil disobedience as a remedy against the political practice of racial segregation.

Many young blacks, however, held the view that peaceful protests in consideration of the sweeping injustice and daily police brutality would lead to nowhere. For that reason, many of them were attracted by the militant struggle against discrimination that was led by figures such as Malcolm X, who was a proponent of separation and self-sufficiency from white America, as opposed to the full integration that people like Martin Luther King advocated. All in all, the protests radicalized in the late 1960s, also due to the advancing activism for civil rights of white students, leftists and young insurgents, who felt associated with the arising counterculture. Or, as Luca Prono states: "The campaign for civil rights was a dynamic force that shook American society during the whole decade" (189).

\section{Student Protests: From the Campuses to the Streets}

In the springtime of the year 1968 protests erupted at Columbia University in New York when student Bob Feldman discovered Columbia's affiliation with an institute closely related to the U.S. Department of Defence, thereby supporting America's war in Vietnam. The uprisings, which lasted several weeks, were a part of student protests all across America and Europe.

The American student activism was born at the University of California in Berkeley and gave rise to the counterculture of the 1960s, which called into question the basic foundations of American society. The so-called Free Speech Move- 
ment spread to hundreds of campuses and "was a source of inspiration to activists in the diverse coalition of the New Left, which gathered civil rights, anti-war, women's and gay liberation movements" (Prono 198).

The escalation of violence in Vietnam became a specific target of criticism and university campuses were the site of anti-war marches, demonstrations and committees. Students demanded the dissociation from institutions which were built on racism and discrimination and "stressed the importance of genuine human relations as an alternative to the alienation of modern society" (Prono 198). Moreover, the Free Speech Movement was closely linked to the Civil Rights Movement and called for racial cooperation and integration. Luca Prono concludes that "the Free Speech Movement had a key role in the development of the 1960s counterculture and the struggle for civil rights" (189). The 1960s, then, can be described as a time of political and social upheaval and the date of foundation of a counterculture which was about to leave an enormous imprint on the following decades.

Braunstein and Doyle argued that "[t]he Sixties counterculture in the United States didn't come out of nowhere" (8). Focusing first on discrimination against African Americans, the movement soon spread to address issues confronting other ethnic groups, women, homosexuals and the disabled. Through criticism about America's involvement in the Vietnam War and a general suspicion of the U.S. military policy, the newly formed anti-war movement unsettled the American establishment. "A general sense of frustration among the young radicals" (Cornea 89 ), which led to an ultimate breach with the institutional authorities, was cemented after the disappointments over the Democrats support of the war, the assassinations of key leaders such as Kennedy, King and Malcolm X and a political swing to the right after Richard Nixon's election in 1968. The contrasts between the rebellious youth and the old-established, conservative faction increasingly intensified and a generation gap developed that was fundamental for the explanation of Stanley Kubrick's success and the contrary receptions of the final sequence of 2001: A Space Odyssey.

\section{"Jupiter and Beyond the Infinite": Between Drugs and Cinematic Subversion}

One of the most commented, disputed and legendary sequences in film history is "Jupiter and Beyond the Infinite" in Stanley Kubrick's motion picture 2001: A Space Odyssey. But why has especially this sequence been so popular among young Americans and why did it become an expression of opposition for the $1960 \mathrm{~s}$ counterculture?

Many establishment critics such as fantasy writer John Brosnan tried to trace the sequence's success merely back to the psychedelic experiences that many intoxicated, young moviegoers had in particular during the final Stargate sequence 
(Cornea 83). Other film critics like Stanley Kauffmann, however, argued that the success of the sequence cannot simply be explained with hallucinogenic effects and attributed the adoption of the film by counter-cultural youth movements to Stanley Kubrick's unconventionality and his subversive use of cinematic devices (Palmer 16-17). In the following analysis, I will try to pursue the question to what extent the sequence's success among the youthful generation is a product of its psychedelic and mind-extending effects and to what extent "Jupiter and Beyond the Infinite" can be considered as a reflection on the social circumstances of the 1960s.

\section{A Literal Trip}

The press labelled Stanley Kubrick's oeuvre as a film "for grooving, not understanding," a "psychedelic experience" and the "ultimate trip" (Chion 43). "Trip" certainly is a keyword of the 1960s culture as well as of the final sequence in 2001, which also became known as cosmic trip. And indeed, the film, especially the Stargate sequence, became a cult attraction among a young generation seeking for consciousness-raising experiences. Psychedelic drugs, in particular LSD, were extremely fashionable for the youthful generation and "recreational drug use in the auditorium was commonly reported" (Palmer 14).

Especially during astronaut Bowman's rapid journey, reports of altered states of consciousness and colorful visions seem plausible. The interaction between multicolored light effects, the conveyance of speed and the depiction of abstract imagery, accompanied by creepy and frightful sounds of György Ligeti's "Atmospheres," made this particular scene so appealing for young viewers seeking for maximum trip. Referring to the Stargate sequence, film critic Stephen Mamber states that "[n]o more hallucinatory and dreamlike a segment has ever appeared in a mainstream film," and that "2001's early reputation as a 'trip' movie was not entirely undeserved" (61).

Additionally, director Stanley Kubrick succeeded in enhancing the impression of a trip with the application of specific cinematic methods. Kubrick deliberately used the point-of-view shot during the voyage as visual angle to let the spectator take astronaut Bowman's position. As a result the literal trip appears more realistic and personal, and the viewer is directly integrated in the happenings. The application of several jump cuts leads over to close-ups of Dave Bowman's face. His facial expression changes intensively in the course of the journey, and his seemingly serene and calm countenance turns into a panic-stricken, fearful face with widely opened eyes and mouth. Once the journey ends, Bowman seems to be in a dream-like state close to unconsciousness. Due to the character's modification of mental and physical being, parallels with young viewers that had the experience of a similar but drug-related trip, seems reasonable and logic. 
A term that is frequently used when talking about "Jupiter and Beyond the Infinite" and altered states of mind is escapism. According to Christine Cornea, the final sequence, accompanied by chemical intoxication was central to a movement's "serious attempts at imagining/creating a different or alternative world" (83-84). The gentle floating of the black monolith in the universe, in the very first scene of the sequence, conveyed a feeling of weightlessness on the one hand and invited young viewers on the other hand to immerse in a world beyond rationality and the imaginable. During the 20-minute voyage many young viewers abandoned their touch with reality and certainly also used the sequence to escape from the misery of the actual world. In the next sections of this chapter, I will elaborate on the question of what they actually tried to flee from and how their criticism of the modern world was constituted.

Quite a few young people used the film, particularly the "Jupiter and Beyond the Infinite" sequence, to turn themselves on under the influence of mindchanging drugs (Cornea 83-83; Palmer 14). For that reason the sequence can be understood as a social phenomenon of the 1960s youth culture, which lined up in related forms of cultural entertainment such as rock concerts that functioned with similar audiovisual tools. In contrast to this mere hedonistic use of the sequence, the rebellious nature was already at this place indicated by the attempt of a quite noticeable number of young viewers to apply "Jupiter and Beyond the Infinite" as an escapist retreat from the misery of the actual world. Nevertheless, I would call this sort of subversion rather unintentional. In the next chapter, I will show that there was indeed direct and conscious use of subversive elements.

\section{Kubrick vs. Hollywood}

The recognition of the film as "an attempt at metaphysical philosophy" (Hunter qtd. in Agel 215) by counter-cultural critics already suggests that the popularity of "Jupiter and Beyond the Infinite" could hardly entirely be explained with its supposedly hallucinogenic effects. However, I will return to critics and perceptions of the sequence and a more elaborate analysis of the social context later and start my analysis with Kubrick's unusual usage of cinematic and stylistic devices.

The most visible subversive element in the depiction of the Stargate sequence is director Stanley Kubrick's omission and violation of established industry standards. Film critic and author R. Barton Palmer states that it is hard to imagine "how Kubrick could have further undermined the ideological presuppositions of Hollywood storytelling" (16). One of the most obvious breaks with mainstream conventions in the 25-minutes long sequence is the absence of any kind of dialogue and speaking. Thereby, the traditional narration, with its "narrative driven by and centred on character" (Palmer 16), and the emphasis on human relations retreats to the background. As a result, the focus of the sequence shifts to audiovisual impressions. 
A close examination of the character Dave Bowman seems useful here in order to show the distinction between how characters were presented in conventional Hollywood productions and how Kubrick portrayed the character in the final sequence of 2001. In "Jupiter and Beyond the Infinite," Bowman appears heteronomous and as subordinate to human evolution. Contrary to characters in established Hollywood films, Bowman is not depicted as the master of his own fate but takes up a passive role, whereby he has no active power of intervention. The effect of this portrayal is that the focus shifts and that the subordination of humans comes into view once again.

An additional cinematic method is Stanley Kubrick's use of contrasts and visual extremes. This device becomes particularly apparent in the director's contrast between the scenes of the floating monolith and Bowman's rapid journey. In the first scene, the shots of the levitating monolith and of Jupiter and its moons, conveys an impression of slowness and gentleness. In contrast to that, in the literal sense of the word, astronaut Bowman's colorful voyage implies an opposing feeling of speed, fear and uncertainty.

Another visible contrast is the opposition between the futuristic, abstract and alien imagery during the journey and the old-fashioned room at the end of the sequence that seems rather familiar. This fairly unconventional use of contrasts serves various purposes. Stanley Kubrick provokes, shocks and even tries to ridicule the audience with contrariety, delusion and the depiction of the unexpected. Furthermore, he defies the Hollywood convention of predictability by showing the unforeseen. A further implication of this contrastive technique is the absence of coherence of the story and the causally link of the plot. Thus, this form of depiction serves as another deliberate trespass against Hollywood standards.

Another stylistic device that immediately leaps to the eye and has also been interpreted as breaking with industry conventions is Kubrick's extraordinary choice of colors. During Bowman's voyage, shortly before his landing, various colorful pictures of a planet are shown and with every cut a new combination of exclusively contrasting, neon colors, is presented. The planet seems alienated by these artificial and unnatural colors and these images provoke the viewers with their almost aching intensity and glariness.

Moreover, Stanley Kubrick sends viewers on a journey into the unknown and irritates them purposely. Kubrick presents pictures that raise essential questions about life only to leave them ultimately unanswered. Whereas in Hollywood films the pictures mostly speak for themselves and the viewer's interpretation is often determined by a clear message and logical images, the Stargate sequence works in an entirely different way. There are no clear answers but irritation about the displayed pictures. For instance, why do seven flashing diamonds appear in the sky above the alien planet or what does the appearance of the Star Child mean? With the deliberate omission of answers, Kubrick leaves the audience with an ample scope for personal interpretation, a topic to which I will return. 
The end of the sequence, which is also the end of the movie, distinguishes it fundamentally from traditional Hollywood film endings: While Hollywood movies generally end with a narrative closure - be it a happy or tragic ending - "Jupiter and Beyond the Infinite" works differently. It does not become explicit if the ending is meant to be happy, neutral or even sad, and also at this point it comes down to personal interpretation. Bowman's death does not, as one could have expected, constitute the ending but the birth of the Star Child, or Bowman's reincarnation respectively, and Kubrick succeeds once again in provoking irritation with an unexpected cinematic device. Hence, it can be stated that the Stargate sequence features a variety of unorthodox cinematic devices that explicitly isolate the film from established mainstream conventions and also foster the controversial discussion about the sequence.

\section{Perception of the Sequence}

The generation gap during the 1960s might not only help to explain the success of the sequence, "but to an important degree its critical reception as well" (Palmer 17). The discussion about "Jupiter and Beyond the Infinite" initiated a debate between a traditional mainstream faction on the one side and the counterculture on the other. I would argue that this debate about the final sequence of 2001: $A$ Space Odyssey symbolizes the generation gap and the division of the American society in the 1960s. I will begin my analysis of the perception of the sequence with a brief examination of the establishment critics. After that, I will present the young 1960s generation's perception of the sequence and explain why it has been so popular, particularly among the youth.

\section{Establishment}

The majority of conservative film critics of the 1960s could not identify with the sequence because conventional standards did not apply and they criticized director Stanley Kubrick blisteringly for his violation of mainstream industry conventions. Stanley Kaufmann argued that "unlike the usual Hollywood product, it did not provide enough in the way of customary structural elements (particularly a main character to focus the story)" (qtd. in Palmer 18). The mainstream reviewers were convinced that Kubrick ignored his talent because he did not, as afore-mentioned, adjust to certain standards and "had proven either unable or unwilling to provide the film with a causally linked plot leading to an exciting, last-minute conclusion" (Palmer 19). Especially the "Jupiter and Beyond the Infinite" sequence, which also constitutes the end of the film, was met with disapproval and misinterpretation. In this context, journalist Jeremy Bernstein wrote: "after reading the book, I realized 
that I really hadn't 'understood' the film, and I had especially not understood the ending" (qtd. in Nelson 106). Referring to the fierce criticism of establishment critics, Joseph Gelmis was convinced that Kubrick's movie was a film of "such extraordinary originality that it upset the members of the critical establishment because it exists outside their framework of apprehending and describing movies" (qtd. in Agel 264).

\section{Counterculture}

The success of "Jupiter and Beyond the Infinite" with the young audience in general and the counterculture in particular "went far beyond the purview of what might be properly called the aesthetic" (Palmer 14). While the "sweeping rejection of those structures and themes so customary in the American commercial cinema certainly challenged the analytical and critical acumen of journalists and reviewers at the time" (Palmer 16), young film critics and moviegoers of an alternative culture praised exactly this rejection and the sequence soon became one of the key manifestations of cultural opposition.

In other words, Stanley Kubrick's dissociation of traditional Hollywood conventions and his unorthodox use of cinematic devices reflect the counterculture's ideas of rebellion against rationality. As mentioned above, the 1960 s were a time of political, social and cultural upheaval and youth revolt. The sequence quickly caught on with the counterculture youth audience open to a contemplative viewing experience of a film, suggesting that the way to personal enlightenment was to free one's mind of the militaristic, reactionary and conservative status quo. In this context, "it is easy to see how the non-rational and creative force in the final sequence of 2001 spoke to a younger generation fighting for change and attempting to break away from institutional authorities that had brought them the futile war in Vietnam" (Cornea 89). Stanley Kubrick "had something different to say, in the largest sense of that term, and had found a different way to say it" (Palmer 16) and therewith captured the right tone of the countercultural movement. Similar to Kubrick and his unusual piece of art, young people across the country felt the necessity to reject middle-class values and institutions. Thus the film and particularly "Jupiter and Beyond the Infinite" became "the source of a special knowledge that distinguished them [young viewers] from their parents and 'square' adults in general" (Palmer 14).

A further socio-political aspect that illustrates the counterculture's positive reception of the final sequence of 2001: A Space Odyssey is Kubrick's deliberate dodging of dichotomies. The traditional classification into good and bad was avoided and it was left to the viewers to decide whether Bowman and his mission were well intentioned or not. While in established Hollywood productions public enemies, communists and oppositionists usually embodied the evil, Kubrick's 
dissolution of dichotomies was received favourably by young Americans who were tired of stylized enemy stereotypes.

Another aspect that explains the sequence's popularity among young Americans feeling associated with the counterculture is the aforementioned possibility of subjective interpretation. In an interview with Playboy, Kubrick states that: "I intended the film to be an intensely subjective experience. ... You're free to speculate as you wish about the philosophical and allegorical meaning of the film" (Nordern 47-48). Christine Cornea also recognizes this subjective potential of interpretation, in particular in the Stargate sequence: "However, my own view is that 2001 encouraged an active engagement on the part of the spectator, which is perhaps most clearly evidenced in the confoundingly abstract imagery in the long final sequence" (87).

Many young viewers derived from their personal interpretation of the happenings in "Jupiter and Beyond the Infinite" subjective messages. Yet, many of these viewers interpreted Bowman's speedy journey and his transformation into the Star Child as a symbol for renewal and change. This common interpretation found an echo in the counterculture's attempts of reformation and transformation of the American political, social and cultural life. Other young spectators transferred their desire for freedom to the sequence and recognized in the rebirth the liberation from exterior influences and the possibility of broadening one's mind. According to Barton R. Palmer, "[m] any reported undergoing religious conversions, rather than experiencing altered states, during the film's famous twenty-fourminute, dialogue-free final sequence" (14).

Yet not every interpretation of the sequence was optimistic. A common, more critical interpretation was that the interaction between death and birth in the final scene could "also be read as a symbol of recurrence" (Cornea 89) and quite a number of young viewers deduced that this was a symbol of human conformism. However, I would not attribute the appreciation of Kubrick's technique to a single message but rather generally to his rejection of dichotomies and the overall possibility for viewers to abstract an individual and subjective message from the film.

\section{Conclusion}

The popularity of the sequence "Jupiter and Beyond the Infinite" in Stanley Kubrick's 2001: A Space Odyssey among young viewers can be traced back to different reasons. Many young spectators certainly used the sequence and especially the hallucinogenic light effects during Bowman's rapid journey as a psychedelic experience and as an escape from reality. These experiences were often reinforced by excessive drug-taking. However, it would be naive to attribute the Stargate sequence's success among young moviegoers to its use of mind-expanding effects only. It is indeed much more. Stanley Kubrick produced an exceptional piece of art that captured the tone of the U.S. counterculture and young viewers in general, 
who recognized themselves in the critical, subversive and provoking tone of the movie. The counterculture that developed out of anger and frustration felt for the conservative, racist and militaristic climate in the USA was addressed by Kubrick's non-conformist avoidance of established standards and conventions. Moreover, the controversy about the final sequence of 2001 certainly can be seen as a reflection of the social circumstances of America in the 1960s. The success of Stanley Kubrick's legendary sequence can be explained with its double aspiration of entertainment and contemporary, intellectual statement. The sequence was like the decade: provocative, colorful and rebellious.

\section{Works Cited}

Agel, Jerome, ed. The Making of Kubrick's 2001. New York: Signet, 1974. Print.

Braunstein, Peter and Michael William Doyle. Image Nation: The American Counterculture of the 1960s and '70s. New York: Routledge, 2002. Print.

Cornea, Christine. "Spaced Out: Between the 'Golden Years." Science Fiction Cinema: Between Fantasy and Reality. Edinburgh: UP, 2007. 75-110. Print.

Chion, Michael. Kubrick's Cinema Odyssey. London: BFI Publishing, 2001. Print.

Fernandez, Chino. "The Tet Offensive." America in Revolt during the 1960s and 1970s. Ed. Rodney P. Carlisle, and J. Geoffrey Golson. Santa Barbara: ABC-CLIO, 2007. 101-19. Print.

Mamber, Stephen. “Kubrick in Space.” Stanley Kubrick's 2001: A Space Odyssey: New Essays. Ed. Robert Kolker. New York: Oxford UP, 2006. 55-68. Print.

Nelson, Thomas Allen. Kubrick: Inside a Film Artist's Maze. Bloomington: Indiana UP, 2000. Print.

Nordern, Eric. "Playboy Interview: Stanley Kubrick." Stanley Kubrick Interviews. Ed. Gene D. Phillips. Jackson: U of Mississippi P, 2001. 47-74. Print.

Palmer, Barton R. "2001: The Critical Reception and the Generation Gap." Stanley Kubrick's 2001: A Space Odyssey: New Essays. Ed. Robert Kolker. New York: Oxford UP, 2006. 13-27. Print.

Prono, Luca. "Free Speech Movement." America in Revolt during the 1960s and 1970s. Ed. Rodney P. Carlisle, and J. Geoffrey Golson. Santa Barbara: ABC-CLIO, 2007. 189-206. Print.

Trevino, Marcella Bush. "Kent State." America in Revolt during the 1960s and 1970s. Ed. Rodney P. Carlisle., and J. Geoffrey Golson. Santa Barbara: ABC-CLIO, 2007. 121-34. Print. 